\title{
THE COURSE OF THE OXIDATION OF THE ALDOSE SUGARS BY BROMINE WATER
}

\author{
By H. S. Isbell and C. S. Hudson
}

ABSTRACT

The optical rotation of a buffered glucose solution upon bromine oxidation rises to a point which corresponds approximately with the rotation of the delta gluconic lactone; then the rotation decreases to a minimum value at a rate corresponding to the hydrolysis of the delta lactone; and finally the rotation slowly increases to a point corresponding to the equilibrium rotation of gluconic acid. These changes agree qualitatively with the hypothesis that the delta gluconic lactone is formed in solution immediately after the oxidation of the sugar by bromine water. Apparently the 1,5 ring form of glucose is oxidized directly to the 1, 5 gluconic lactone, but the authors believe that further data must be obtained before this mechanism is definitely established.

The oxidation of various sugars was followed by the same method and similar changes were observed which indicate that the aldose sugars in general are oxidized by bromine water in slightly acid solution to the delta lactones rather than to the sugar acids as previously believed.

\section{CONTENTS}

I. Introduction

II. Bromine oxidation of glucose

III. Bromine oxidation of various sugars

1. Oxidation of $d$-galactose.

2. Oxidation of $l$-arabinose

3. Oxidation of $d$-xylose

4. Oxidation of lactose.

\section{INTRODUCTION}

The oxidation of the aldose sugars to monobasic acids by bromine water, a classical reaction which was originally introduced by $\mathrm{H}$. Kiliani, ${ }^{1}$ has been considered as evidence for the aldehydic structure for glucose and related sugars. The mechanism of the reaction has been explained on the hypothesis that in an aqueous solution of glucose an aldehyde tautomer exists in small quantity in equilibrium with the normal form. As this aldehyde form is used up by oxidation the equilibrium disturbance causes a new portion to be formed; finally, all the sugar reacts as an aldehyde. ${ }^{2,3,4,5}$

\section{$\mathrm{CH}_{2} \mathrm{OH}(\mathrm{CHOH})_{4} \cdot \mathrm{CHO}+\mathrm{Br}_{2}+\mathrm{H}_{2} \mathrm{O} \rightarrow \mathrm{CH}_{2} \mathrm{OH}(\mathrm{CHOH})_{4} \cdot \mathrm{COOH}+2 \mathrm{HBr}$ Aldose Aldonic acid}

\footnotetext{
1 H. Kiliani, Ann., vol. 205, p. 182, 1880; also Kiliani and Kleeman, Ber., vol. 17, p. 1298, 1884. 2 Pringsheim, "Zuckerchemie," Leipzig, p. 8, 1925.

3 Crammer, "Les Sucres," Gaston Doin \& Co., Paris, p. 22, 1927.

4 Armstrong, "The Carbohydrates and the Glucosides," Longmans, Green \& Co., London, p. 67, 1924.

B Haworth, "Constitution of Sugars," Edward Arnold \& Co., London, p. 4, 1929.
} 
This concept is based upon the fact that when 1 molecule of bromine reacts with 1 molecule of glucose the final products which have been isolated are 2 equivalents of hydrogen bromide and 1 molecule of gluconic acid. The isolation of these products does not determine the mechanism of the reaction because the sugar after oxidation may pass through a number of steps prior to the separation of the final products. This is particularly true in regard to the sugar acids as they are interconvertible with their lactones. In $1914 \mathrm{Nef}^{6}$ showed that gluconic acid forms two lactones rather than one. The second lactone he called a beta lactone, while the one previously known was considered as a gamma lactone; Nef's beta lactone is now believed to be a 1,5 or delta lactone. The two lactones contain five and six membered oxygen rings in which respect they are analogous to the gamma and the normal forms of glucose. A freshly prepared aqueous solution of gluconic acid on standing forms an equilibrium between the acid and the two lactones. As shown by Levene and Simms? the delta lactone is formed rapidly while the gamma lactone is formed more slowly. By utilization of the different rates of formation either lactone may be separated at will. In the past the sugars have been regarded as being oxidized to the acids, the lactones being secondary products. It will be shown in the next paragraph that this fundamental concept must be altered in order to account for the experimental facts which are given.

\section{BROMINE OXIDATION OF GLUCOSE}

In a previous paper ${ }^{8}$ the authors give an improved method for the preparation of aldonic acids which differs from previous methods in that during the oxidation of the sugar with bromine water a slightly acid reaction is maintained by means of a buffer. The reaction is rapid and nearly quantitative and hence it is possible to follow the course of the reaction by the optical rotation of the solution. When the reaction was followed in that manner a series of peculiar changes in optical rotation was observed. As illustrated in Curve I of Figure 1 the specific rotation of a buffered solution of glucose on oxidation increases in a few minutes to a maximum value, then decreases rapidly to a minimum and thereafter slowly increases and finally becomes constant.

When the oxidation is interrupted by removing the free bromine a mutarotation of the solution occurs. If the bromine is removed with sodium thiosulphate the mutarotation which follows is very rapid, as illustrated in Curve III of Figure 1, but if the bromine is removed without altering the acidity of the solution the specific rotation changes more slowly, as in Curve II. This may be accomplished by shaking the solution with olive oil. Since the bromine combines directly with the oil there are no objectionable by-products and no marked changes in acidity. If the bromine is removed with olive oil shortly after the specific rotation of the original oxidation mixture reaches a maximum, the rotation of the resulting solution decreases to a minimum and thereafter slowly rises to a constant value. These changes are entirely different from the changes characteristic of a

6 Nef, Ann., vol. 403, p. 325, 1914.

7 Levene and Simms, J. Biol. Chem., vol. 65, p. 31, 1925

8 C. S. Hudson and H. S. Isbell, J. Am. Chem. Soc., vol. 51, p. 2225, 1929; also in B. S. Jour. Research, vol. 3 , p. 57, 1929. 
gluconic acid solution. The specific rotation of a freshly prepared solution of gluconic acid (Curve IV, fig. 2) decreases from a negative value to zero, and finally becomes positive, and thereafter increases very slowly. Inasmuch as the specific rotation of gluconic acid is less than that of any known form of glucose if gluconic acid were formed initially the specific rotation would decrease rather than increase. The initial rise in the optical rotation of the solution of glucose on bromine oxidation shows that gluconic acid is not the primary product of the oxidation of glucose in acid solution. As a consequence, we must seek a new interpretation for the mechanism of this important reaction. With the experimental conditions used in the reaction under discussion a certain ring form of the sugar
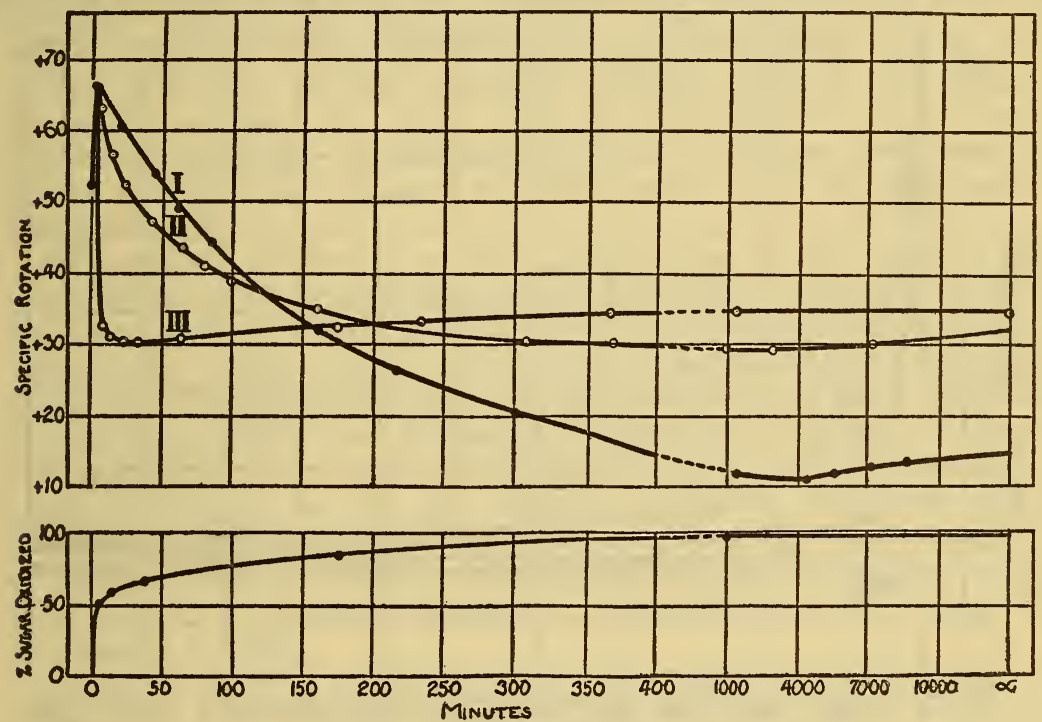

Figure 1.-Bromine oxidation of glucose

$I$, changes in the specific rotation of the sugar solution during oxidation.

II, changes in the specific rotation of a portion of the solution after interrupting the oxidation by removing the free bromine with olive oil.

III, changes in the specific rotation of a portion of the solution after removing the free bromine with sodium thiosulphate.

might be oxidized rather than the hypothetical aldehydic form. If the sugar ring is not broken a gluconic lactone would be formed directly as indicated by the following equation:

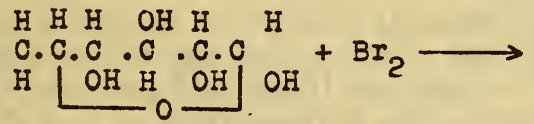
$\mathrm{H} \mathrm{H} \mathrm{H} \mathrm{OH} \mathrm{H}$
HO C.C.C.C.C.C" $+2 \mathrm{HBI}$
$\mathrm{H} \mathrm{OH} \mathrm{H}_{\mathrm{O}} \mathrm{OH}$

HO

According to this concept the oxidation of glucose by bromine consists in the transfer of each of the two hydrogen atoms associated with the terminal carbon atom in a molecule of glucose to a molecule of bromine, giving a net result of 1 molecule of gluconic lactone and 2 molecules of hydrogen bromide. If the normal form of glucose $(1,5)$ were oxidized in this manner the delta or 1,5 gluconic lactone would be formed. This would explain the changes in rota- 
tion observed during the bromine oxidation of the sugar. Thus, if the oxidation product is the delta lactone the initial rise in specific rotation is caused by its formation, the subsequent rapid decrease in rotation being due to its hydrolysis to gluconic acid, the hydrolysis proceeding until a quasi equilibrium is established between the delta lactone and the acid, thus accounting for the minimum value, and simultaneously a second or gamma lactone is formed very slowly. The formation of the second lactone, continuing long after equilibrium is established between the delta lactone and the acid, adequately explains the slow rise in rotation.

A comparison of the changes in optical rotation of 7 glucose on bromine oxidation, of gluconic acid, and the delta lactone, is given in Figure 2, which shows graphically the close agreement in rotation

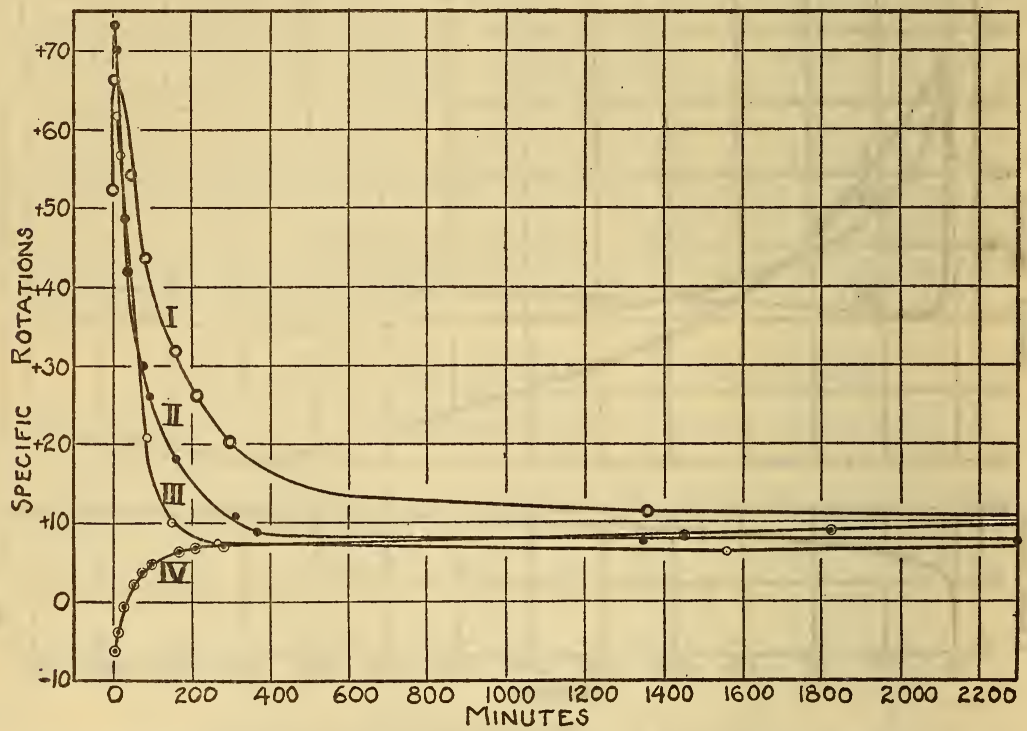

FIGURE 2.-Curves showing a comparison in the specific rotation of the oxidation product from glucose with gluconic acid and its delta lactone

$I$, a buffered glucose solution upon bromine oxidation (Table 1).

II, rotation of the oxidation product from glucose after bromine oxidation in which further oxidation was stopped by removing the excess bromine (sample A, Table 2).

III, mutarotation of the delta gluconic lactone (Nef).

$I V$, mutarotation of a buffered solution of gluconic acid (Table 5).

and reaction rates of the oxidation product with the delta gluconic lactone.

Although in Curve I a small amount of glucose is continuously being oxidized into the delta lactone which causes the rotation to be higher than that which would be observed if this did not occur, the change in rotation is very similar to the mutarotation of Nef's ${ }^{9}$ lac-

'Nef, Ann., $\nabla 01.403$, p. 325, 1914. The following data are given: $0.8010 \mathrm{~g}$ of the " $\beta$ " gluconic lactone was dissolved in $19.3220 \mathrm{~g}$ of water and the following rotations were read in a $1 \mathrm{dm}$ tube at $20^{\circ} \mathrm{C} . ; 12 \mathrm{~min}$ utes after solution, $+2.48^{\circ},[\alpha]_{D}^{20}=61.7 ; 13$ minutes, $+2.46^{\circ} ; 21$ minutes, $+2.88^{\circ} ; 24$ minutes, $+2.22^{\circ} ; 11 / 2$ hours, $+0.83^{\circ} ; 21 \frac{1}{2}$ hours, $+0.4^{\circ} ; 41 \frac{1}{2}$ hours, $+0.31^{\circ} ; 26$ hours, $+0.25^{\circ}$ (minimum); 46 hours, $+0.32^{\circ} ; 70$ hours, $+0.39^{\circ}$; 114 hours, $+0.40^{\circ}$; from which we calculated the additional values for $[\alpha]_{D}^{20}: 13$ minutes, $+61.4^{\circ} ; 21$ minutes, $+56.9^{\circ} ; 24$ minutes, $+55.4^{\circ} ; 90$ minutes, $+20.7^{\circ} ; 150$ minutes, $+10.0^{\circ} ; 270$ minutes, $+7.74^{\circ} ; 1,560$ minutes, $+6.24^{\circ} ; 46$ hours, $+7.99^{\circ} ; 70$ hours, $+9.74^{\circ} ; 114$ hours, $+10.0^{\circ}$. 
tone shown in Curve III. Curve II shows the change in specific rotation of the oxidation product from glucose after bromine oxidation in which the excess bromine was removed by olive oil. The rotations were calculated as given in the experimental portion of the paper. After the first 30 minutes, Curve III drops more rapidly than Curve II, while for the first 30 minutes Curve II drops slightly more rapidly than Curve III. This is due to the fact that the sample shown in Curve II is buffered with sodium acetate and acetic acid, while Nef's solution shown in Curve III is not buffered; initially the sample shown in Curve II is slightly more acid than Nef's solution on account of the acetic acid in the buffer, but as the lactone shown in Curve III hydrolyzes it becomes more acid than the solution shown in Curve II. Curve IV shows the mutarotation of a buffered solution of gluconic acid. The specific rotation starts with a negative value and changes at approximately the same rate as the rotations of the oxidation product and the delta lactone. After 400 minutes the value reaches approximately that shown in Curves II and III. In the latter portion of all the curves a gradual rise in rotation occurs, as one would expect, since the final products are the same.

The marked similarity of the mutarotation of the oxidation product (Curve II) to the mutarotation of the delta lactone (Curve III), together with the dissimilarity to the mutarotation of gluconic acid (Curve IV) indicates that the rapidly mutarotating substance is the delta or 1,5 gluconic lactone. If we interpret the fact that lactone formation precedes the formation of gluconic acid to indicate that one ring form of the sugar is oxidized directly to the lactone, we can not say whether or not the particular form of the sugar which is oxidized is the predominating form in solution. Nevertheless it is of interest that the delta or 1,5 lactone is found in solution after the oxidation of a solution containing normal glucose which supposedly contains a 1,5 ring.

Since the lactone appears in solution immediately after the oxidation, if the sugar ring is broken it must be closed again within a few minutes. This might be accomplished by means of an intermediate compound which has the property of condensing rapidly to form the lactone. But regardless of the exact mechanism whereby the lactone is formed, its appearance prior to that of gluconic acid gives a new conception for the oxidation of the aldose sugars in slightly acid solution.

\section{BROMINE OXIDATION OF VARIOUS SUGARS}

Inasmuch as the specific rotations of the lactones of the aldose sugars differ in value, it is reasonable to assume that the corresponding sugars on bromine oxidation should show similar variations in the values of their specific rotations. Our experimental results indicate that such is the fact. In addition, our observations have shown that in each case a series of changes occurs which indicates that the delta lactones are the first products which can be detected and that the acids which appear subsequently are secondary products resulting from the hydrolysis of the lactones. Some of the lactones which are indicated by these observations are not known at present, but will undoubtedly be prepared in the future. 
The experimental method was essentially that outlined for glucose. In each case the same quantities by weight of the reagents and sugar (anhydrous) were used. The rotations were read in a $1 \mathrm{dm}$ tube and calculated to the specific rotations which are based upon the weight of sugar. The temperatures were maintained as near $20^{\circ}$ as possible, but the large amount of heat liberated in the reactions caused some variations. Further experiments are in progress wherein the conditions are more rigidly controlled, the results of which will be treated in subsequent publications.

\section{OXIDATION OF $d$-GALACTOSE}

The changes in rotation which occur on the oxidation of galactose (fig. 3, Curve I) resemble those found for glucose in that the specific
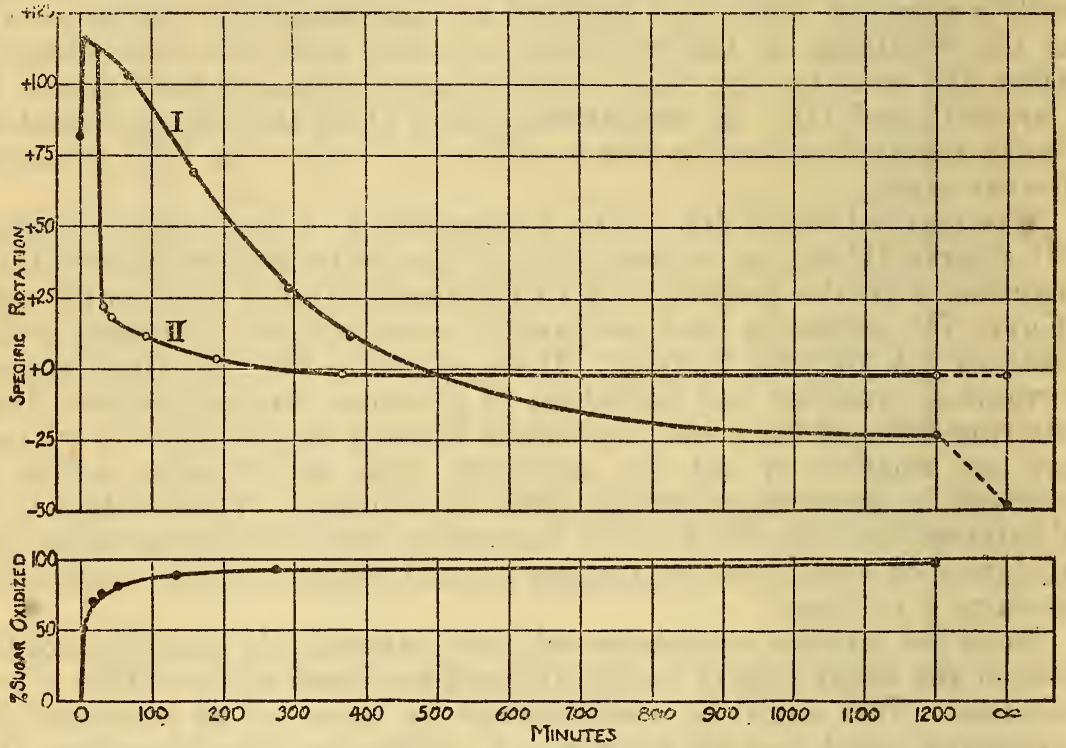

FIGURE 3.-Bromine oxidation of galactose

$I$, changes in the specific rotation of the sugar during the oxidation.

$I I$, changes in the specific rotation of a portion of the solution after interrupting the oxidation by removing the bromine with sodium thiosulphate.

rotation increases initially, then decreases rather rapidly for several hours. Subsequently the rotation decreases very slowly to a constant negative value which corresponds to the equilibrium condition between the acid and the lactones. Obviously the highly dextro rotatory oxidation product is not galactonic acid which exhibits a negative specific rotation ${ }^{10}\left([\alpha]_{D}^{20}=-10.6\right)$. The rotation of the oxidation product decreases on standing while the rotation of galactonic acid first increases, reaching a maximum in about two hours, then slowly decreases. ${ }^{11}$ The initial rise in the rotation of the solution after bromine oxidation indicates that the delta galactonic lactone (presumably formed) is more dextro rotatory than the sugar. The

10 Ruff and Franz, Ber., vol, 35, p. 948, 1902.

11 Levene and Simms, J. Biol. Chem., vol. 65, p. 41, 1925. 
rapid decrease in rotation is caused by the hydrolysis of this lactone which proceeds until a quasi equilibrium with the free acid is established. As the gamma lactone continues to form, the negative rotation of the solution increases because the specific rotation ${ }^{12}$ of the gamma lactone $\left([\alpha]_{\mathrm{D}}^{20}=-77\right)$ is even more negative.

\section{OXIDATION OF 1-ARABINOSE}

The changes in rotation which occur on the oxidation of arabinose (fig. 4, Curve I), are very similar to those found for galactose. The marked similarity might be expected from the closely related structures. The delta arabonic lactone which at present is not known also
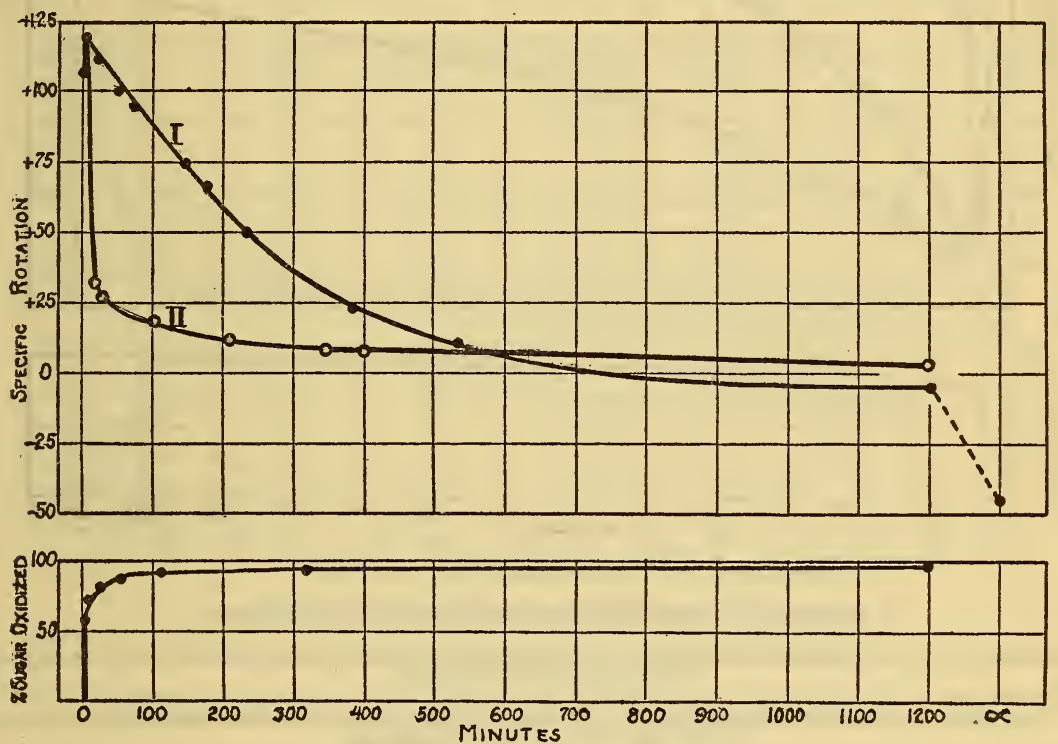

Figure 4.-Bromine oxidation of arabinose

I, changes in the specific rotation of the sugar during the oxidation.

II, changes in the specific rotation of a portion of the solution after interrupting the oxidation by removing the bromine with sodium thiosulphate.

appears to be more dextro rotatory than the free sugar. The specific rotations of $l$-arabonic acid and its gamma lactone are reported as $[\alpha]_{\mathrm{D}}^{20}=-9^{13}$ and $[\alpha]_{\mathrm{D}}^{20}=-73,{ }^{14}$ respectively. A comparison of the specific rotation of the free acid with specific rotation of the sugar during the oxidation shows that the acid is not the initial oxidation product.

\section{OXIDATION OF $d$-XYLOSE}

Although the changes in rotation which occur on the oxidation of $d$-xylose, as shown by the specific rotation curves (fig. 5) appear to be quite different from those previously given, they indicate that similar phenomena are taking place. The curves appear different because the first product, presumably the delta lactone, has a negative rotation,

14 Fischer and Piloty, Ber., vol. 24, p. 4219, 1891. 
causing the rotation to decrease initially. As this strongly negatively rotating lactone is hydrolyzed to the free acid the negative specific rotation decreases to zero. After becoming positive it increases as the dextro rotating gamma lactone ${ }^{15}$ is formed. The delta xylonic lactone is not known at present, but these results indicate it has a strongly negative specific rotation.
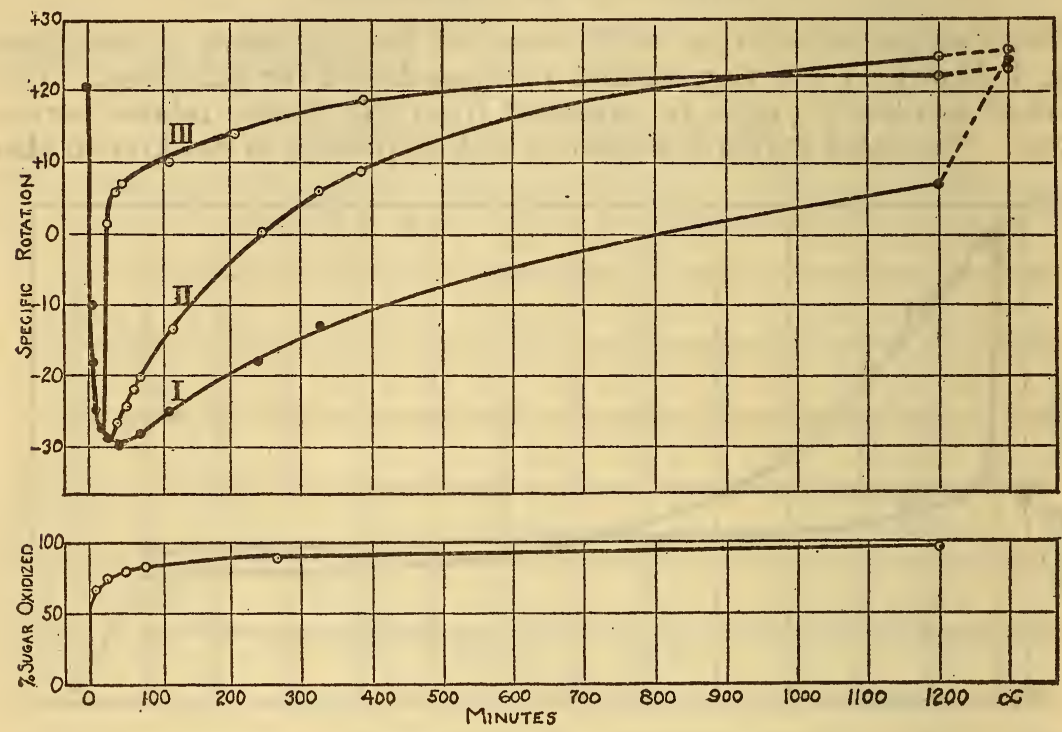

Figure 5.-Bromine oxidation of xylose

$I$, changes in the speciflc rotation of the sugar during the oxidation.

$I I$, changes in the specific rotation of a portion of the solution after interrupting the oxidation by removing the bromine with olive oil.

III, changes in the specific rotation of a portion of the solution after interrupting the oxidation by removing the bromine with sodium thiosulphate.

\section{OXIDATION OF LACTOSE}

The oxidation of lactose is of particular interest because the fourth carbon in this sugar is substituted and the corresponding monobasic acid can not form a gamma lactone. The changes in rotation (fig. 6, Curve I) show that only a single lactone is formed. The oxidation curve for lactose differs from the other sugars in that it does not give the final slow change in rotation characteristic of the gamma lactones. The type of specific rotation curve obtained with this sugar is additional evidence supporting the hypothesis that the delta lactones are formed prior to the sugar acids in the course of the oxidation of the normal aldose sugars by bromine water. The lactone of lactobionic acid is not known in the crystalline state. The initial rise in rotation shown in Curve I indicates that the rotation of this lactone is more dextro than the rotation of lactose.

16 According to Clowes and Tollens, $[\alpha]_{\mathrm{D}}^{20}=+74.4$. Ann., vol. 310, p. $175,1900$. 


\section{EXPERIMENTAL DETAILS}

The oxidation of glucose was conducted in the following manner: $271 / 2 \mathrm{~g}$ of $\alpha$ - $d$-glucose monohydrate (25 g of anhydrous sugar), $37.5 \mathrm{~g}$ of crystalline sodium acetate and $2.5 \mathrm{ml}$ of glacial acetic acid were dissolved in sufficient water to give $244 \mathrm{ml}$. After 18 hours the rotation was measured at $20^{\circ}$ with a Bates saccharimeter; the solution was then cooled to $+8^{\circ}$ and $8.75 \mathrm{ml}$ of bromine were added, making the total volume of the solution $250 \mathrm{ml}$. The solution was shaken vigorously until the bromine was completely dissolved, which required one or two minutes. The temperature rose rapidly to $20^{\circ}$ where it was maintained by occasional immersion of the flask in an
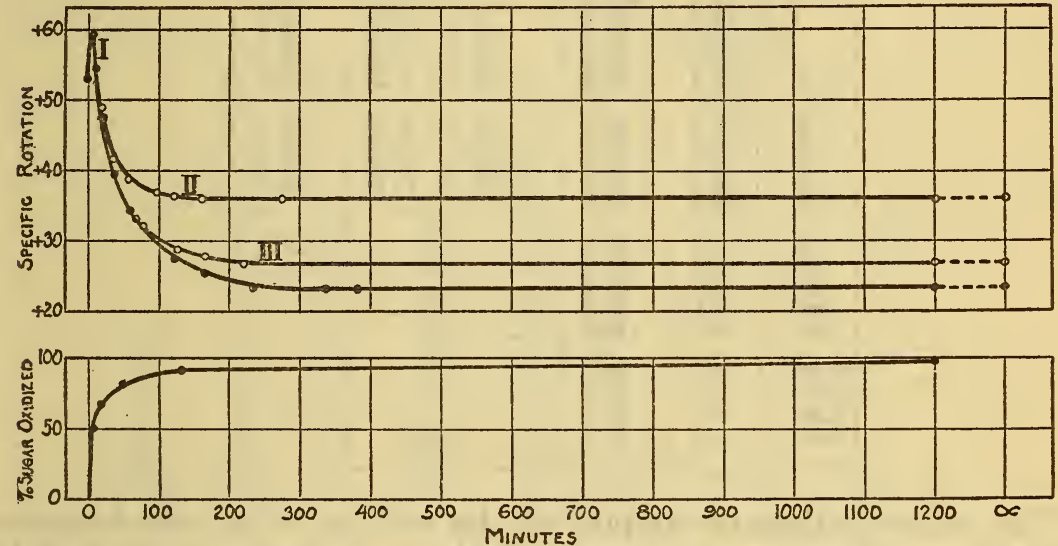

FIgURe 6.-Bromine oxidation of lactose

I, changes in the specific rotation of the sugarduring the oxidation.

II and III, changes in the specific rotations obtained from portions of the solution after interrupting the oxidation at different times by removing the bromine with olive oil.

ice bath. Since it was desired to obtain readings as soon as possible the solution could not be kept in a thermostat, and, consequently, it was not possible to control the temperature very closely during the early stages of the reaction. A portion of the oxidation solution was transferred to a $1 \mathrm{dm}$ polariscope tube and the rotation read every few minutes. The readings are given under "Rotation of the solution," Table 1. Simultaneously, samples of the oxidation solution were pipetted into small glass-stoppered flasks which contained $25 \mathrm{ml}$ of a 10 per cent potassium iodide solution, and the free bromine was determined by titration with sodium thiosulphate. The amount of bromine used in the oxidation of the sugar was obtained by the difference in the titration of a blank which contained the same quantity of bromine, but did not contain any glucose, and the titration of the sample. The results are expressed in Table 1 as $\mathrm{ml}$ of N/10 bromine used per $\mathrm{ml}$ of the sugar solution.

$$
99675-32-2
$$


TABLE 1.-Bromine oxidation of glucose at $20^{\circ} \mathrm{C}$.

$1 \mathrm{dm}$ tube, international sugar degrees $25 \mathrm{~g}$ glucose $(\alpha \rightleftarrows \beta)$

37.5 g sodium acetate $\left(\mathrm{NaC}_{2} \mathrm{H}_{3} \mathrm{O}_{2} \cdot 3 \mathrm{H}_{2} \mathrm{O}\right)$

$2.5 \mathrm{ml}$ glacial acetic acid

Water to make a total volume of $250 \mathrm{ml}$ after the addition of $8.75 \mathrm{ml}$ bromine

\begin{tabular}{|c|c|c|c|c|c|}
\hline \multicolumn{3}{|c|}{ Rotation of the solution } & \multicolumn{3}{|c|}{ Bromine determination } \\
\hline$\Delta \mathrm{T}$ & $\circ \mathrm{s}$. & {$[\alpha]_{\mathrm{D}}^{20}$} & $\Delta \mathrm{T}$ & $\begin{array}{l}\text { Bromine } \\
\text { used per } \\
\text { ml sugar } \\
\text { solution }\end{array}$ & $\begin{array}{c}\text { Sugar } \\
\text { oxidized }\end{array}$ \\
\hline$\underset{0}{\text { Minutes }}$ & 15.0 & +52.4 & Minutes & $\begin{array}{l}\text { ml N/10 } \\
\text { solution }\end{array}$ & Per cent \\
\hline $\begin{array}{l}4 \\
6.5 \\
9 \\
22\end{array}$ & $\begin{array}{l}19.0 \\
19.0 \\
18.7 \\
18.0\end{array}$ & $\begin{array}{r}\text { T6. } \\
66.4 \\
65.3 \\
62.9\end{array}$ & $\begin{array}{c}4 \\
14 \\
32 \\
56\end{array}$ & $\begin{array}{l}5.85 \\
6.65 \\
7.30 \\
8.25\end{array}$ & $\begin{array}{l}52.7 \\
59.9 \\
65.7 \\
74.3\end{array}$ \\
\hline $\begin{array}{l}28 \\
38 \\
46 \\
54 \\
62\end{array}$ & $\begin{array}{l}17.4 \\
15.9 \\
15.5 \\
14.8 \\
14.0\end{array}$ & $\begin{array}{l}60.8 \\
55.5 \\
54.1 \\
51.7 \\
48.9\end{array}$ & $\begin{array}{r}172 \\
1,375 \\
5,940 \\
7,200\end{array}$ & $\begin{array}{r}9.30 \\
10.60 \\
11.00 \\
11.10\end{array}$ & $\begin{array}{r}83.7 \\
95.4 \\
99.0 \\
100.0\end{array}$ \\
\hline $\begin{array}{r}85 \\
159 \\
216 \\
300 \\
1,360\end{array}$ & $\begin{array}{r}12.5 \\
9.1 \\
7.5 \\
5.8 \\
3.3\end{array}$ & $\begin{array}{l}43.7 \\
31.8 \\
26.2 \\
20.3 \\
11.5\end{array}$ & & & \\
\hline $\begin{array}{l}4,320 \\
5,713 \\
7,200 \\
8,640\end{array}$ & $\begin{array}{l}3.0 \\
3.3 \\
3.6 \\
3.8\end{array}$ & $\begin{array}{l}10.5 \\
11.5 \\
12.6 \\
13.3\end{array}$ & & & \\
\hline
\end{tabular}

The mutarotations of samples of the solution after the bromine oxidation of glucose are given in Table 2. Samples A, B, and C were taken at different times, and the oxidation stopped by removing the excess bromine by shaking with olive oil. In this manner the excess bromine is removed very quickly without changing the acidity of the solution. A small amount of decolorizing carbon was added and the mixtures were filtered through dry filter papers directly into polariscope tubes. The polariscopic readings for each sample are recorded under "S." The "per cent of glucose" oxidized was obtained from the amount of bromine used as given in Table 1. The unoxidized glucose is the difference between the amount originally added and the amount oxidized by the bromine water. The rotation of the unoxidized glucose is computed upon the assumption that the specific rotation of the unoxidized glucose remains constant and equal to $+52.4^{\circ} .16$ The "lactone formed" per $\mathrm{ml}$ of solution is calculated from the bromine used, by multiplying the values for the $\mathrm{ml}$ of $N / 10$ bromine used (see Table 1) by the factor 0.0089 . The rotation of the "lactone formed" is equal to the difference between the rotation of the solution and the rotation of the unoxidized glucose, and the specific rotation of the "lactone" is equal to this difference expressed in circular degrees divided by the weight of lactone per ml of solution.

16 The calculations were made upon the assumption that the mutarotation of the solution was due solely to the oxidation product. Probably certain forms of the sugar are more easily oxidized than others. Hence one form may be preferentially oxidized and the equilibrium of the various forms of the sugar may be displaced. This equilibrium disturbance would cause the rotation of the unoxidized sugar to change as the sugar approached equilibrium. The preliminary results indicate that any error which may arise from an equilibrium disturbance under the specific experimental conditions is small, but the subject is being investigated further. 
TABLE 2.-Mutarotation of samples after bromine oxidation of glucose

(The excess bromine was removed with olive oil)

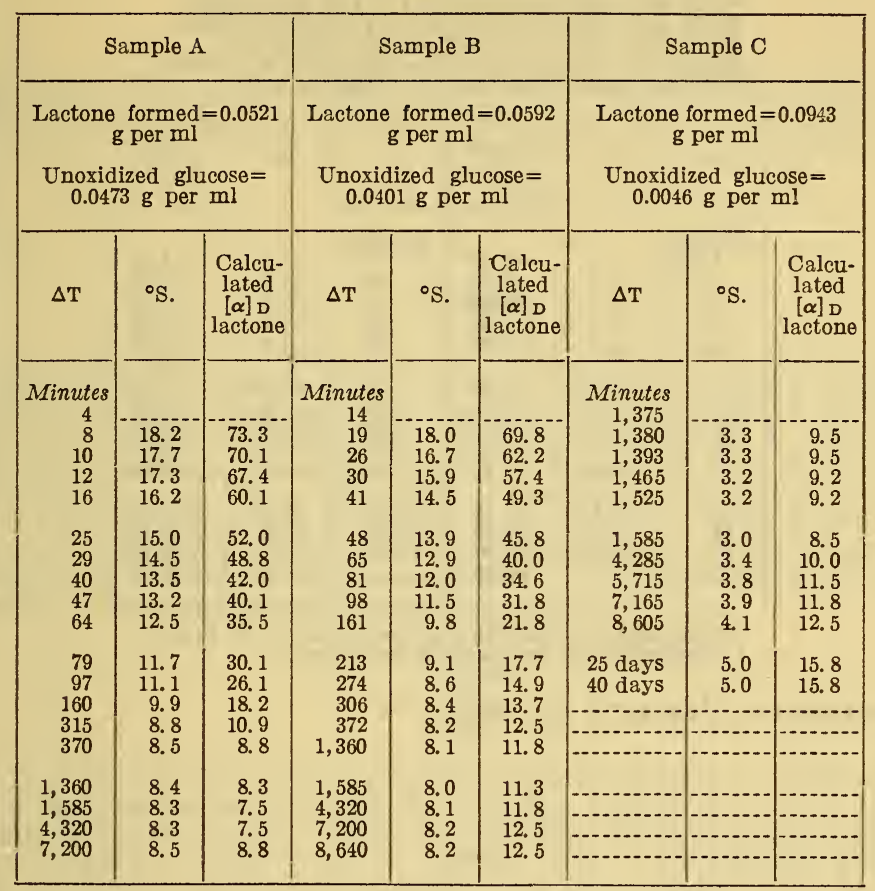

TABLE 3.-Comparison of optical rotations of the oxidation product (sample A) with Nef's lactone ${ }^{1}$

\begin{tabular}{|c|c|c|c|}
\hline \multicolumn{2}{|c|}{ Oxidation product } & \multicolumn{2}{|c|}{$\begin{array}{l}\text { Nef's less stable } \\
\text { gluconic lactone }\end{array}$} \\
\hline Time & {$[\alpha]_{\mathrm{D}}^{20}$} & Time & {$[\alpha]_{\mathrm{D}}^{20}$} \\
\hline $\begin{array}{c}\text { Minutes } \\
6 \\
8 \\
10 \\
14 \\
23\end{array}$ & $\begin{array}{r}+73.3 \\
+70.1 \\
+67.4 \\
+60.1 \\
+52.0\end{array}$ & Minutes & $\begin{array}{r}+61.7 \\
+61.4 \\
+56.9\end{array}$ \\
\hline $\begin{array}{r}27 \\
95 \\
158 \\
1,585\end{array}$ & $\begin{array}{r}+48.8 \\
+26.1 \\
+18.2 \\
+7.5\end{array}$ & $\begin{array}{r}24 \\
90 \\
150 \\
1,560\end{array}$ & $\begin{array}{r}+55.4 \\
+20.7 \\
+10.0 \\
+6.24\end{array}$ \\
\hline
\end{tabular}

${ }^{1}$ See footnote 9, p. 330 . 
TABLE 4.-Mutarotation of gluconic acid at $20^{\circ} \mathrm{C.} .^{1}$

$1 \mathrm{dm}$ tube, International sugar degrees.

0.0139 mole, sodium gluconate or $13.9 \mathrm{~m}] \mathrm{N} / 1$ solution.

0.0137 mole, sodium acetate or $1.86 \mathrm{~g} \mathrm{NaC}_{2} \mathrm{H}_{3} \mathrm{O}_{2} \cdot 3 \mathrm{H}_{2} \mathrm{O}$.

$0.0184 \mathrm{~mole}$, acetic acid $=1.02 \mathrm{ml}$ glacial acetic acid.

$0.0278 \mathrm{~mole}$, hydrobromic acid $=4.06 \mathrm{ml} 6.85 \mathrm{~N} / 1$ solution.

Sufficient water to make a total volume of $25 \mathrm{ml}$.

\begin{tabular}{|c|c|c|c|c|c|}
\hline$\Delta \mathrm{T}$ & ${ }^{\circ} \mathrm{S}$ & {$[\alpha]_{\mathrm{D}}^{202}$} & $\Delta \mathrm{T}$ & ${ }^{\circ} \mathrm{S}$ & {$[\alpha]_{D}^{20}$} \\
\hline $\begin{array}{c}\text { Minutes } \\
4.5 \\
5.5 \\
6.5 \\
9 \\
12\end{array}$ & $\begin{array}{l}-1.8 \\
-1.7 \\
-1.6 \\
-1.6 \\
-1.2\end{array}$ & $\begin{array}{l}-6.29 \\
-5.94 \\
-5.60 \\
-5.60 \\
-4.20\end{array}$ & $\begin{array}{c}\text { Minutes } \\
87 \\
100 \\
113 \\
129 \\
170\end{array}$ & $\begin{array}{l}+1.3 \\
+1.3 \\
+1.6 \\
+1.7 \\
+1.8\end{array}$ & $\begin{array}{l}+4.55 \\
+4.55 \\
+5.60 \\
+5.94 \\
+6.29\end{array}$ \\
\hline $\begin{array}{l}15 \\
19 \\
26 \\
30 \\
36\end{array}$ & $\begin{array}{l}-1.0 \\
-.7 \\
-.5 \\
-.2 \\
+.05\end{array}$ & $\begin{array}{l}-3.50 \\
-2.45 \\
-1.75 \\
-.70 \\
+.17\end{array}$ & $\begin{array}{r}210 \\
286 \\
1,455 \\
1,825 \\
6,195\end{array}$ & $\begin{array}{l}+1.95 \\
+2.0 \\
+2.4 \\
+2.6 \\
+3.7\end{array}$ & $\begin{array}{r}+6.82 \\
+6.99 \\
+8.39 \\
+9.09 \\
+12.94\end{array}$ \\
\hline $\begin{array}{l}44 \\
54 \\
64 \\
75\end{array}$ & $\begin{array}{l}+.4 \\
+.6 \\
+.85 \\
+1.1\end{array}$ & $\begin{array}{l}+1.40 \\
+2.10 \\
+2.97 \\
+3.85\end{array}$ & $\begin{array}{r}7,575 \\
8,160 \\
13,920 \\
\end{array}$ & $\begin{array}{l}+3.85 \\
+4.0 \\
+4.6 \\
+5.0\end{array}$ & $\begin{array}{l}+13.46 \\
+13.99 \\
+16.09 \\
+17.49\end{array}$ \\
\hline
\end{tabular}

1 Equivalent concentrations to those in sample C, Table 2. 2 Calculated upon the weight of the lactone.

WASHINGTON, January 11, 1932. 